\title{
Making climate change public? A dramaturgically inspired case-study of learning through transition management
}

\author{
Katrien Van Poeck* \\ Centre for Sustainable Development, \\ Ghent University, \\ Poel 16, B-9000 Gent, Belgium \\ Email: katrien.vanpoeck@ugent.be \\ *Corresponding author

\section{Joke Vandenabeele} \\ Laboratory for Education and Society, \\ University of Leuven, \\ Andreas Vesaliusstraat 2 - bus 3761, B-3000 Leuven, Belgium \\ Email: joke.vandenabeele@ppw.kuleuven.be
}

\section{Gert Goeminne}

Centre for Sustainable Development,

Ghent University,

Poel 16, B-9000 Gent, Belgium

Email: gert.goeminne@ugent.be

\begin{abstract}
This article reports on a case study of a 'transition arena' established by an urban government in order to realise a climate neutral city through transition management. We study this case as a non-formal learning setting in which educational and political processes are intertwined. We draw on Noortje Marres' conceptual distinction between 'privatisating' and 'public-ising' forms of issue formation and use a dramaturgical analytical framework that allows us to grasp how the design of a setting shapes and transforms not only the issue at stake but also the public involved in it. The development of a climate literate public, we argue, cannot be limited to learning predefined answers but should rather enable people to think critically in relation to taken-for-granted norms by opening-up democratic spaces where people can discuss and discover options through the exploration, evaluation, and critique of emerging ideas and the creative contribution to their development.
\end{abstract}

Keywords: education; climate change; global warming; transition management; controversy; environmental literacy; case study; public pedagogy; dramaturgical analysis.

Reference to this paper should be made as follows: Van Poeck, K., Vandenabeele, J. and Goeminne, G. (2017) 'Making climate change public? A dramaturgically inspired case-study of learning through transition management', Int. J. Global Warming, Vol. 12, Nos. 3/4, pp.366-385. 
Biographical notes: Katrien Van Poeck is a Postdoctoral Researcher at the Centre for Sustainable Development (Ghent University) where she conducts empirical research on practices and policymaking in the field of environmental and sustainability education and theoretical work on the relation between sustainability education and politics. She is particularly interested in questions of democracy, controversy, citizenship, public involvement and the relation between research, policy and practice.

Joke Vandenabeele is a Lecturer at the Faculty of Psychology and Educational Sciences (University of Leuven) and a Senior Researcher at the Laboratory for Education and Society. She teaches non-formal education, citizenship education and the role of art and culture in communities today. The key topics of her research are: citizenship education, social and biographical learning, community development, practices of solidarity in relation to living with differences in cities and the search for sustainable development as a public issue.

Gert Goeminne is a Postdoctoral Researcher at the Centre for Sustainable Development (Ghent University). He investigates the politics of sustainability from a science and technology studies perspective. His main research interests pertain to the hybrid socio-technical character of sustainability issues such as climate change, thereby investigating how understandings and representations of these problems are inherently linked to the ways in which we choose to address them.

\section{Introduction}

In this article, we analyse a so-called 'transition arena' established by an urban government aimed at realising a climate neutral city through a participatory 'transition management' process (see e.g. Kemp et al., 2007; Scrase and Smith, 2009). We scrutinise this case with a particular interest in the educational dimension of such a participatory practice. Although the transition arena is not primarily defined as an educational setting, the actors involved repeatedly refer to 'learning' (e.g. 'learning from each other' and 'learning by doing') as an important leverage to realise climate targets. Indeed, processes of social change are often regarded to be learning challenges for individuals, groups and communities (Biesta, 2004; Simons and Masschelein, 2006, 2009). This tendency to translate 'societal problems' into issues that need an 'educational solution' [Simons and Masschelein, (2006), p.395] pre-eminently applies to ecological issues and sustainable development (Postma, 2004; Ferreira, 2009; Van Poeck et al., 2014). A sustainable world or a climate neutral city emerge then as challenges that can be met by teaching and learning the proper solutions, desirable attitudes, correct behaviour, required competences, etc. Policy-makers as well as scholars argue for 'learning our way out' of unsustainability (Finger and Asún, 2001). Paavola et al. (2004) highlight that contemporary societal evolutions require learning processes that aim at collectively creating new knowledge in 'innovative knowledge communities' (Nonaka and Takeuchi, 1995; Engeström, 1999; Bereiter, 2002) and at transforming and developing existing ideas and practices. Particularly in the context of sustainability, there is an emerging field of research highlighting the need to break away from existing world views and notions of sustainability and development and to explore and create new ones (Finger and Asún, 
2001; Sumner, 2003; Clover and Hill, 2003; Vare and Scott, 2007; Jackson, 2011). Jackson (2011) argues for 'transformative learning', a process that pushes us to think and act anew by questioning the assumptions behind established world views, visualising alternatives and testing them in practice.

However, the role of learning in tackling societal problems is the subject of an ongoing discussion in educational scholarship. Critics argue that sustainability issues cannot be approached as if they were solely a matter of more or better learning processes. Considering that these issues are often very uncertain and controversial (both in factual and normative terms) ${ }^{1}$ and drastically affect our planet and its inhabitants it is argued that, first and foremost, sustainability issues raise democratic challenges (e.g. Wildemeersch and Vandenabeele 2007; Simons and Masschelein, 2010; Biesta, 2012; Sund and Öhman, 2014). Biesta (2012), for instance, points out the risk of replacing politics with education by conceiving of the latter as a matter of instructing - of telling people 'what to think, how to act and what to be'. Such a one-sided focus on instruction and learning tends to render social and political problems into responsibilities of individuals, obscuring the plurality, differences and collective concerns at stake. Therefore, he argues for a 'public pedagogy' that contributes to creating a public sphere where people can take initiative, begin something new and do something that has not been done before and that takes into account the irreducibly contested character of the issues at stake in contemporary social and political problems.

In the remainder of this article, we first further elaborate the idea of creating a public sphere around sustainability issues drawing on Marres' (2005) research on how 'issues call publics into being'. Next, after going into the dramaturgical framework used, we present our case study of the transition arena as a specific setting within which educational and political, democratic processes are entangled. In particular, we explore how this setting affects the room for 'public-isation' (Marres, 2005) of the issue of climate neutrality. Our analysis is not aimed at evaluation or developing evidence-based, generalised knowledge but rather at documenting and in-depth understanding of this particular practice. Finally, we connect the conclusions drawn from this empirical analysis to the discussion about education's role in building a more sustainable world. Our aim is to contribute to this ongoing debate both empirically and theoretically. First, by presenting a detailed dramaturgical analysis of a situated practice at the 'intersection of politics and pedagogy' [Biesta, (2012), p.685]. Secondly, by conceptualising climate literacy and education about global climate change as a process that moves beyond teaching and learning predefined answers but rather requires a public space where controversy can be enacted and explored and where new, creative possibilities for the future might open-up.

\section{Making issues public}

We draw on Marres' distinction between the 'privatisation' and 'public-isation' of issues as a conceptual framework to guide our investigation. As we will show, these notions allow us to address two major concerns raised in the above elaborated debate about the role of education in tackling societal problems: the importance of keeping the process of public formation open and of taking irreconcilable controversy seriously.

Following the work of John Dewey, Marres (2005) claims that it is always an issue that 'calls a public into being'. Members of political communities are not in first instance 
connected by way of shared or opposing opinions and interests, she argues, but by issues. The public thus consists of a variety of actors who are affected by an issue in which they are jointly and antagonistically implicated. An issue qualifies as a public affair, then, if both private interests (attachments to matters of individual concern, such as an affluent lifestyle or a profitable business) and public interests (attachments to matters of collective concern, such as climate change or immigration) are entangled. Put differently, Marres emphasises that it is precisely the irreconcilability between varied private and public interests inevitably and inseparably coming together in the face of certain problems that turns the latter into political issues. Thus, drawing on Dewey's account of the public's genesis, she conceptualises democratic politics as a particular practice of issue formation: a practice dedicated to finding a settlement for affairs, thereby taking into account the joint and antagonistic attachments at stake in which individual life conditions and the common good are entangled.

In this vain, Marres distinguishes between 'public-ising' and 'privatising' forms of issue formation. She defines public-isation as an attempt to articulate issues, draw actors into it and formulate a possible settlement for it. In contrast to privatisation, publicisation implies the broadening instead of limiting of the involvement of actors in a given affair. Yet, public-isation cannot be reduced to the inclusion of actors since such an approach would fail to acknowledge the issue's contested content - epitomised in the scientifically irreducible question 'what is at stake?' (Goeminne, 2011) - as a crucial dimension for public involvement. Therefore, public-isation also entails the proliferation of conflict, making room for contestation and controversy as an occasion to enact the irreconcilability of the actors' attachments. Privatisation, by contrast, is characterised by the containment of conflict and contestation. Instead of paying attention to antagonistic attachments, privatisation limits the scope to consensual issue definitions that assemble shared attachments. Those that exclude them are left out of account and the exclusivity among the multiplicity of concerns, claims and ideals is sidestepped. A key distinction is, thus, whether or not processes of issue formation make the point at which attachments prove exclusive manifest. Whereas public-isation prepares the ground for a demonstration of which attachments should bind us more strongly than others and, in doing so, focuses joint and antagonistic attachments into a specific yet accessible point of contention, privatisation closes down issues for intervention by outsiders [Marres, (2005), p.130]. For an issue definition to open up an affair for public involvement and not just for partisan support, Marres argues, it must hold together both shared and exclusive attachments. The constraints antagonistic attachments put on each other cannot be ignored or downplayed but must be taken seriously. This is not about reconciling the irreconcilable; on the contrary: it is about publicly demonstrating that something must give way by taking into account the divergent attachments of actors.

A public does not emerge 'out of the blue', Marres argues, but requires a lengthy and laborious process of organising a public around an issue. It is this process that is the focus of our analysis. Focussing on the ways in which the public-isation and privatisation of affairs work upon issues and issue definitions, we investigate how, in this particular transition arena, a public is composed around the issue of a climate neural city. In order to do so, however, an analytical framework is needed that puts the setting in which public participation takes place centre stage. 


\section{Dramaturgical analysis: a focus on the performativity of participatory settings}

In the context of policy deliberation, Hajer (2005) argues that the analysis of participatory practices should not merely focus on the types of arguments that are raised but also include the conditions for dealing with issues by focusing on the setting in which public participation takes place. It is through these settings - which are never neutral - that the public is given shape and gets transformed (Gomart and Hajer, 2003) in particular non-neutral ways. As Cornwall and Coelho (2007) argue, participatory practices are always "infused with power relations" (p.11) and "much depends on who enters these spaces, on whose terms and with what epistemic authority" (p.5). A setting's characteristics not only define who has access but also what counts as relevant information, reasonable arguments, and legitimate decisions (Nahuis, 2009). In other words, it is the particular design of the setting in which utterances are made that affects "what is said, what can be said, and what can be said with influence" [Hajer, (2005), p.626]. In line with recent developments in the field of science and technology studies, Hajer (2005, p.642) thus argues for a 'performative' perspective in researching participatory settings emphasising that "the public becomes what the setting makes it". Such a performative perspective draws attention to the co-production of public and issue - that is to say to the concrete ways in which the design of a setting creates a very particular public around a very particularly framed issue. Following Jasanoff's (2004) account of the social and natural order as standing in a relation of co-production, and in line with Marres' (2005) perspective on public formation, we conceive of the issue-public duality as an emergent result, rather than a starting-point of a particular participatory or educational dynamic. We are thus interested in examining what the setting does in shaping and transforming both those who are engaged in it - the public - as well as in shaping and transforming that what is considered to be at stake in it - the issue (Gomart and Hajer, 2003). Therefore, we will not only investigate the actors involved (or excluded) but also examine how the particular design of the setting affects which concerns, knowledge claims, values, expertise, opinions, discourses, and arguments are regarded legitimate and which are not. As such, dramaturgical analysis allows tracing how power courses through every dimension of participatory practices and making sense of the micro-politics of encounters in such a participatory arena (Cornwall and Coelho 2007) and of the interrelatedness of educational and political processes therein.

Starting from such a performative perspective, several authors (e.g. Hajer, 2005; Gomart and Hajer, 2003; Nahuis, 2009) developed analytical frameworks for the study of public participation drawing on metaphors borrowed from theatre and drama: actors, script, setting, attributes, staging, performance, acts, and scenes. Dramaturgical analysis, Hajer clarifies, shows how scenes are scripted and staged as well as how the variety of players subsequently act within and upon those scripts and staging. Combining elements of the frameworks elaborated by Hajer and Nahuis, we analyse the setting of the transition arena by employing the following concepts. First, 'scripting' (Hajer, 2005) refers to the efforts made for determining the characters in the play as well as the cues for appropriate behaviour. Our analysis of the transition arena's script also entails the setting's 'access conditions' (Nahuis, 2009), that is the way settings give access to some actors while others are part of the audience (i.e. those who are able to observe the performance and are indirectly involved) or excluded altogether. Second, we focus on the 'staging' (Hajer, 2005) of the setting which refers to the deliberate organisation of an 
interaction through tools, methodologies, activities, formal and informal rules of the game, etc. Here, we also include the artefacts that are used and that co-determine the physical situation in which the interaction takes place. Third, we analyse the 'performance', i.e. the way in which the contextualised interaction itself produces social realities such as understandings of the issue at stake, knowledge, and new power relations (Hajer, 2005).

As we will show, our focus on a particular setting and how its design gives way to shaping and transforming the concerns, knowledge claims, values, expertise, opinions, discourses, and arguments that are taken into account allows us to analyse whether and, if so, how the transition arena keeps the process of public formation open and deals with irreconcilable controversy around the issue of climate neutrality. Drawing on this analysis, we will also address the relation between educational and political/democratic processes within this setting in order to further conceptualise a 'public pedagogy' in the face of sustainability issues.

\section{Case study: a 'transition arena' for a climate neutral city}

The case we analyse is a 'transition arena' that has been established by the urban government of Ghent (Belgium) as one of the measures aimed at realising the city's climate action plan. Following the cautious and modest Covenant of Mayors, a European Commission initiative, the ambition is to transform Ghent into a climate neutral city by 2050. In its communication about this policy goal, the city repeatedly emphasises that it cannot achieve this objective on its own. The 'Climate Alliance of Ghent' has been set up so as to foster support and engagement of citizens, businesses, civil society organisations, educational institutions, etc. (http://www.gentsklimaatverbond.be). The latter can express their commitment by endorsing the following Charter:
"I am aware that our climate changes, partly due to the emission of greenhouse gasses (particularly carbon dioxide) by humans. In Ghent, too, it is necessary to reduce $\mathrm{CO}_{2}$ emissions. I will do this by cutting back on energy consumption (for housing, transport and food or within my company/organisation) as well as by maximally applying sustainable energy sources. I take the responsibility to pursue climate neutrality by collaborating in the Climate Alliance of Ghent, together with other citizens of Ghent, businesses, organisations,..."

Through diverse initiatives, people are incited to contribute to the realisation of climate neutrality. One of these policy actions is the establishment of a 'transition arena' which aims to involve varied stakeholders in a process of 'transition management'. In the policy document 'Towards a sustainable city: more than a city trip! On transitions and transition management' (Stad Gent, 2011), the urban government describes transition as 'a process of far-reaching, structural changes in the social as well as technical systems of our society that is explicitly connected to a preconceived goal: sustainable development'. The management of transitions is conceived as 'leading', 'steering', and 'facilitating' potential processes of change toward a desired future, grounded in an in-depth understanding of the current situation rather than as a matter of 'control'. Thereby, the urban government draws on a theoretical understanding of transitions (developed by DRIFT $^{2}$ - see below) as an ideal succession of six crucial steps: analysing systems, developing vision ('leitmotifs'), outlining 'transition paths', experimenting, follow-up, 
and embedding. The arena is part of this policy process and has been set up so as to promote the participation of a variety of 'stakeholders'.

\subsection{Methodology}

Our analysis is based on interviews, observations and a review of documents. We interviewed two civil servants: the coordinator and one of the engineers of the city's 'climate team'. As we were not allowed to interview participants ${ }^{3}$, the information gathered through the interviews reflects the perspective of the organisers of the arena (e.g. on the 'scripting' and 'access conditions', on choices made regarding the setting's 'staging', etc.) and not the participants' experience and interpretation. The observations, then, enabled us to register how the organisation of interactions ('staging') took place in practice as well as how both organisers and participants acted within this setting (e.g. the actual 'performance' of contextualised interactions). We observed four activities: three (out of seven) arena meetings with 17-23 participants and the 'Climate Forum' that was organised for a broader audience of 90 participants. For practical reasons related to the available period for data collection it was impossible to observe all the arena meetings. However, data triangulation allowed us to use the document analysis (detailed minutes of the meetings, preparatory documents, Powerpoint presentations, etc.) and specific questions during interviews to avoid blind spots in our understanding of the arena's overall activity. Furthermore, we focussed our analysis of the 'performance' dimension on the observed interactions only. The observed activities and the interviews have been video-/audio-recorded with permission of the respondents/participants. Verbatim transcripts of the (originally Dutch-spoken) conversations were complemented with contextual information and descriptions of the observed non-verbal aspects of the setting (gestures, movements, material context, etc.) in field notes. The analytical work started with repeatedly examining the documents, field notes, recordings and transcripts so as to search for sequences containing information as to the scripting, staging, and performance of the arena's setting and about aspects related to the public-isation and privatisation of issues. These sequences were then coded, starting from sensitising concepts rooted in Marres' conceptual distinction between the 'privatisation' and 'public-isation' (cf. below) of issues and expanding this initial coding scheme by identifying aspects of the arena's scripting, staging, and performance that fostered public-isation or privatisation. The qualitative analysis software QSR NVivo was used so as to facilitate data storage, coding, retrieval, and linking. Finally, the analysis made by one of the authors was validated by the co-authors through critical examination of the findings in relation to the empirical material.

Although we are critical about the arena's contribution to creating a public sphere around the issue of a climate neutral city, our purpose is not to characterise the entire case as either 'privatising' or 'public-ising' from an evaluative perspective. Nor do we aim to develop valid, evidence-based knowledge about assumed 'successful' public-ising versus 'failing' privatising practices that are subsequently translated into instructive do's and don'ts for policymakers and practitioners. Rather, our analysis is aimed at an in-depth understanding of this particular practice and wants to invite and inspire the reader to be attentive to how, at specific instances, the public-isation of sustainability issues can be fostered or impeded. Patton (2002, p.129) labels this kind of research as 'orientational qualitative inquiry': an exploratory inductive analysis starting from an explicit theoretical perspective that guides fieldwork and the interpretation of findings. The focus of our 
inquiry is determined by the theoretical framework elaborated above and thus our findings are interpreted and given meaning from that perspective. The aim is elucidation rather than an absolute open-minded discovery of emergent theory: we want to describe specific manifestations of public-isation and privatisation in this particular practice.

In line with the dramaturgic perspective employed, the next three sections present the results of our case analysis in terms of respectively scripting, staging and performance.

\subsection{Scripting}

The driving force behind the arena is the environmental department of the urban government in Ghent, more specifically the engineers belonging to the department's climate team as well as the coordinator of this unit and the director of the department. As a kind of producer of the setting, this team's role is to facilitate and support the arena administratively, logistically, and strategically by preparing meetings, helping to find financial resources, developing step-by-step plans, etc. The team itself is supported and advised by three organisations guiding the transition management process: the Dutch Research Institute for Transitions (DRIFT), the Flemish Institute for Technological Research (VITO) and tri.zone, a consulting agency focusing on sustainable development. Our analysis shows how the climate team, assisted by these organisations, largely determines the characters in the play, the access conditions, and the cues for appropriate behaviour. A key role is attributed to the 17 members of the transition arena who are called 'fresh-thinkers', 'trendsetters', and 'freethinkers'. Among those actors are the alderman for environment, businesspersons ${ }^{4}$ and representatives of youth work, the arts sector, the environmental movement, and the university (e.g. experts in mobility and wastewater). These varied characters are expected to 'co-create and co-implement' the urban government's ambition of a climate neutral city.

\footnotetext{
"Everyone must support the objective but must also be able to help create the objective, so actually it's a sort of co-creation and, if you allow co-creation and if it becomes everyone's baby it is easier to take the step towards co-implementation and meet the shortages of your own leverage."
}

Therefore, it is regarded crucial to engage 'people with a network' - that is, who can reach an audience - who also have the time, the gusto, the knowledge, the creativity and the will and power to 'make a difference' within these networks. As one of the interviewees explained, participants have to be 'interested' and 'convinced', able to think 'positively and constructively' and not 'dominant'. Sometimes, people with very particular skills are sought (e.g. ICT skills or expertise concerning mobility).

Thus, although the city aims to involve a broad range of stakeholders in the co-creation and co-implementation of a climate neutral Ghent, the involvement of actors is arranged in a very particular and limitative way. Specific expectations toward participants serve as a standard to distinguish between those actors who are (to be) given a key role, those who are indirectly involved as part of the audience and those who are ignored altogether. These expectations explicitly guided the selection of participants and, throughout the whole process, the climate team deliberately searched for the 'proper' actors and, when regarded necessary, made the effort to organise a sort of audition.

\footnotetext{
"That's why we organised the climate forum. We thought, [...] we need more people than those sitting in the arena. They are a bit reluctant to appeal to their network, or we find that their network does not include the right people so we
} 
go headhunting and the climate forum was organised specifically for headhunting purposes."

Furthermore, the aforementioned cues for appropriate behaviour provided the basis on which the arena members' actual engagement is judged. For instance, one of the interviewees explained that a particular participant's contribution was regarded 'a bit disappointing' as (s)he is 'fairly negative' and 'does not think positively and constructively'. Some actors are considered more 'valuable' than others, depending on their willingness and ability to contribute to the urban government's ambition of climate neutrality in accordance with the methods and strategies developed by the climate team and transition arena. After all, the raison d'etre of the arena is this very particular policy goal: realising a climate neutral city by 2050 . This objective is considered a 'story' that has to be 'sold'. Put differently, it is put forward as a shared attachment for which partisan support is sought through the arena. The principal aim of the arena is then to realise a 'transition in the minds'. This perspective brings about a particular view on the division of roles between, on the one hand, key actors (i.c. the engineers of the climate team and the 'valuable' fresh-thinkers within the arena) and, on the other, the audience to which the story of a climate neutral Ghent has to be sold.

\begin{abstract}
"One of the reasons why they created my job is also to perform some streamlining and to implement an effective policy to supplement that of the engineers $[\ldots]$ In such a way that we must actually just work out the transition in the minds. [...] In my view that's what it comes down to. The engineers come up with measures that can be implemented. They tell us what is feasible. They perform studies on renewable energy, energy maps. They are also developing all kinds of new, interesting tools, often with European subsidies. But... of course in this way it will not be sold yet, will it? Thus, as such, I consider what we do also as a form of education for sustainable development."
\end{abstract}

Education for sustainable development is about 'selling a story', the interviews elucidate. It is about broadly spreading a particular message of climate neutrality as a shared issue definition, especially towards people that are not (yet) interested or convinced. In line with the view of the Climate Alliance (cf. Charter), the purpose is to raise awareness, to arouse interest and to stimulate people 'to do something'. As the interviewees explained, it is about creating support for the policy objectives and about encouraging inhabitants, businesses, organisations, etc. to take actions that contribute to the realisation of these goals.

\title{
4.3 Staging
}

In line with the transition arena's aim to 'co-create and co-implement' a climate neutral city by 2050 the arena members are invited to define the vision, to formulate targets, and to develop innovative solutions. The organised activities are meetings during which plenary discussions usually alternate with further elaborations in subgroups. During these meetings, slides are shown, brochures are distributed, and notes are discussed. This goes with the intention of the climate team to 'put something on the table' at the start of each meeting (e.g. a systems analysis, results of $\mathrm{CO}_{2}$ monitoring, suggested transition paths, survey results, etc.) in order to 'provide structure' or to 'unlock a response'. For instance, we observed a meeting where participants were asked to provide feedback on the systems analysis that had been prepared by the climate team. This approach, the interviewed 
engineer explained, does not entirely fit in with transition management theory. First, less time was taken for it then prescribed.

\begin{abstract}
"If you really want to do it properly, really thoroughly, then it can easily take you a year. We sorted that out, I think in a few weeks, with a whole load of reports that already existed and in fact the most important items, or conclusions or eye-catchers... [...] We also said from the beginning that it wasn't the intention to make a fully-fledged, entire systems analysis."
\end{abstract}

Furthermore, instead of doing the systems analysis within the arena, in collaboration with the participants, it has been carried out by the engineers of the climate team and, subsequently, presented to the arena for feedback. Key topics of that analysis were presented on 15 slides and the arena members were invited to formulate comments on the text as well as to suggest matching images so as to visualise these topics. In order to complete this task within the space of time provided for the meeting, the participants were given 2.5 minutes to discuss each of the 15 topics of the systems analysis and 0.5 minute to brainstorm about suitable images. One of the coaches kept a close watch on the timing ("It is a bit unpleasant, but we have to, otherwise we won't make it by 9PM."). Subsequently, they were divided in 4 subgroups and invited to formulate 'basic principles' (centred around 'people', 'planet', 'profit' and 'participation') so as to develop a vision concerning the goal to transform Ghent into a climate neutral city. The engineer emphasised that the participants were unwilling to spend more time on it and wanted to move on to concrete actions.

\begin{abstract}
"DRIFT's step-by-step plan requires that you refine the system analysis with the whole group, in such a way that it really gets through to them [...] but people thought it was good that it was presented once, but the second time was too much. [...] However the first time we did not get far enough but people thought refining the system analysis was a waste of time."
\end{abstract}

Transition management in general and this arena in particular, the interviewees argued, follow a two-tiered path of 'studying' and 'doing' for creating new practices, routines and a new system. Transferring and sharing knowledge is considered to be crucial in order to 'learn from each other', to 'grasp the complexity' of the climate-issue and to 'achieve a more or less commensurable level of knowledge' among the actors involved. Therefore, experts were invited to give presentations, participants were encouraged to bring in and share their knowledge and expertise, the climate team brought in the results of (mainly technical) analyses and of working groups or subgroup discussions. These efforts are assumed to lay the foundations for an in-depth study of the issue at stake and, thus, to develop new knowledge and insights. However, the way in which the activities were organised - particularly the rapidity - seems to challenge the aims of studying and co-creating. As our observations indicate and the following excerpt also illustrates, the emphasis is on doing rather than on studying.

\footnotetext{
"We chose a path involving study and action. If you want to achieve climate neutrality in the city or make it totally independent of fossil fuels, you can study the concept for years, [...] but in fact not just society but also politics demands that action is taken quickly and so we are following a parallel path, implementing it at the same time."
}

We observed that the particular staging of this transition arena's setting inhibits a thorough, in-depth exploration of what is 'put on the table'. The organisation of the meetings is focussed at creating a shared definition of a climate neutral city within a 
limited space of time and, subsequently, implementing the proposed actions for realising the devised 'transition paths'. This shuts the door on a collective inquiry into the issue at stake in this arena and the private and public interests entangled in it. The arena's staging does not create sufficient time to reveal, explore and confront the joint and antagonistic attachments through which a variety of actors are caught up in the issue of a climate neutral city and, thus, for a demonstration of which attachments prove mutually exclusive.

\subsection{Performance}

In line with this, we regularly observed manifestations of disagreement among the arena members but these, too, were treated rather superficially. For example, diverging opinions were voiced concerning the balance between social and economic interests; the relation between structural, systemic changes versus small, feasible steps forward; the choice for a narrow focus on 'climate neutrality' (the reduction of greenhouse gas emissions) or a broad one on a 'sustainable city' (including other considerations such as poverty and affordable housing); etc. During these discussions, we observed diverging opinions being voiced, yet, from a perspective of noncommittal pluralism within which conflicting views seem to co-exist peacefully. The diverse concerns, values, knowledge claims, etc. that lie behind them are not made explicit and their possible irreconcilability - that is, the way in which they exclude one another - is not enacted.

Despite these divergent views, the outcome of the transition management process that is, the leitmotifs and transition paths - reflect a very particular understanding of the transition towards a climate neutral city emphasising the positive side effects of climate neutrality, the potential of technological solutions, and the possibility of win-win situations. A closer look at a concrete interaction during an arena meeting helps to grasp how divergent points of view were translated into such a consensual understanding of climate neutrality. As part of the transition management process, the arena members were asked for ideas and suggestions to realise a transition towards climate neutrality and their input was gathered by the climate team into four 'leitmotifs' and 20 'transition paths'. We observed a meeting where the latter were presented and participants had to indicate (by means of stickers) which paths they considered the most important. Afterwards, in subgroups, they were asked to complete two posters. For the first one, aimed at further defining the paths, they had to provide feedback on the description and the targets the climate team had prepared as well as to list preconditions that have to be taken into account. They were given 20 minutes to do so. The second poster focused on actions in order to realise the targets. The arena members were asked to list good practices, possible actions as well as people and organisations they considered crucial partners. This had to be finished in 40 minutes.

We observed a subgroup discussion consisting of four participants: an engineer working for the 'climate team' (C), a former university professor with expertise in wastewater management (W), an entrepreneur owning an energy consultancy company (E), and an employee of the building department of the university (B). They discussed posters about the transition path 'waste is history'. The professor chairs the discussion and starts with a 'confession':

W: Well I should start by confessing that $[\mathrm{C}]$ and I have already been thinking about this a bit. But [...] that doesn't mean that we've got something already, $[\ldots]$ it could go any which way, you know. 
Indeed, during an informal talk before the arena meeting the engineer told us about the intention of the university and the urban government to jointly submit a research proposal on the recycling of wastewater, which has been the main research interest of this professor for a long time. The engineer of the climate team urges the others to start with completing the posters. The professor opens the discussion addressing the first target: 'recording all the waste flows'.

W: I don't think it's that inviting. [...] We know even less about sewers. But solid waste on the other hand: organic waste, [...] plastics, metals and drinking cartons, that kind of things, that's already pretty decent. But everything that disappears into the sewer, that's, I think, what we should be talking about now...

With this intervention, he implicitly connects the broadly defined target to the issue of wastewater management by reducing waste flows to sewage flows. What follows, is a very technical discussion between the professor and the engineer about the fermentation of waste. The other participants do not intervene in this technical discussion. The university employee, however, does bring in a new consideration:

- B: Well, I think that something is missing. It's actually because there is so much throwaway material that there is so much more waste. I see us having to chuck out loads of things because replacing a part in a device is more expensive than just buying a new device. And so we generate an unbelievable amount of waste this way, and while you can say that it's energy friendly, it still needs processing. And why is it cheaper to buy a new device? Because they are made using cheap labour somewhere and in order to fix it here, you have to pay an expensive technician. This ends up generating loads of waste, you know, because you can't actually repair anything. [...]

- E: But then you need a completely different market, don't you, a completely different way of designing devices.

In doing so, she broadens the scope of what is taken into account. Where waste previously emerged as an utmost technical matter, here she emphasises the connection with the economic organisation of our society. In doing so, she draws in new considerations: besides organic waste, sewage, fermentation installations, biogas, incineration, and compost she points out that the issue of waste also involves consumables, labour costs, technicians, the market, and product design. As the response of the energy consultant shows, she thereby demonstrates that some of the attachments at stake (e.g. our consumer society, employment, waste reduction) are mutually exclusive. Thus, her intervention opens-up a space to public-ise the issue of waste. What follows as the discussion continues, however, is a succession of interventions that contribute to the re-containment (privatisation) of what is taken into account. Hence, the issue reappears as a technical matter:

- W: I agree, but, how can I put it... repair work is... [...] We almost have to use the words repair parts [...]. These don't become waste, they're reused. We really should say then: 'repair parts cannot'... in fact 'repair parts may not be waste'.

- C: Yes.

- W: [...] That's what you mean, but how do you say that? Repair, the word repair... [laughs] 
- B: Yes, actually, you have to design things so that they can be repaired.

- W: [...]Let's put it this way: 'repair parts are and can be repaired'...

- $[\ldots]$

- E: Excellent!

- C: Yes, that's just what I was saying: we can actually repair it, but we don't because it costs more to get it repaired than to just replace it.

- W: Can and are repaired. Very good, we've got there. [...]

- B: Yes, but repair parts is an odd concept, what do you actually mean by it?

- C: That they're modular parts that you can replace, you actually replace a part, to repair it.

- B: Oh, OK, I get it...

As such, some of the considerations that had just been taken into account, vanish: labour costs, technicians, and the market give way to the technologically and productionoriented concept of 'repair parts' which allows to sidestep the irreconcilability of the abovementioned concerns, claims and ideals. In the continuation of the conversation, again, the university employee tries to open-up the issue definition by highlighting her concern for waste reduction:

- B: You want to reduce the amount of waste taken to the recycling centre and winding up in the sewers by $80 \%$. I think that's a really good goal to have, but to do it, we're going to need a lot more than...

- W: $80 \%$ is already being given a new lease on life right now.[...] If it's been turned in [for recycling], then it's not waste anymore.

- B: Oh, I don't agree with that.

- E (to B): You're trying to reduce waste, right?

- Again, the concern she draws into the discussion is contained into a technological problem that is in need of an appropriate technological fix: recycling. This time she opposes this privatising move. All the participants get involved in the discussion during which the exclusivity between the different ideals, claims and concerns at stake is further enacted.

- B: What do you all actually mean because I think I see it differently.

- W: The separated types are not thought of as waste any more by [the Flemish waste administration].

- E: So I actually think it's a pretty weak target. But there's still a second target, you know. You could even go back to the days of taking your refillable bottle to the dairy farmer.

- W: But that's not really feasible any more, you know.

- C: No.

- B: But then will we ever be carbon neutral? [...]

After this discussion, the professor asks the engineer to delete a target about completely eliminating incineration from the poster since, he argues, that would render the transition arena 'unreliable' and she does so. 
The discussion comes to an end as the coach that guides this transition arena meeting urges the group to start listing good practices, possible actions, and crucial partners. During this listing exercise the university employee again emphasises the connection of the issue of waste to the economic organisation of our society and the irreconcilability of waste reduction and a consumer society:

- E: It's about creating a context in which companies can do their own thing. [...] Like they've done with solar panels.

- B: Yes, but that context increased consumption. A focus on repairs can create jobs.

- C: We're going to create other types of consumption. You're talking about consuming less, but this is about consuming differently. (emphasis added)

The engineer responds with another privatising intervention: playing on the minimal difference between the Dutch words for 'consuming less' ('consuminderen') and 'consuming differently' ('consumanderen'), she contributes to the creation of an issue definition - reflected in the formulated actions and transition paths - of a climate neutral city that only assembles shared attachments and ignores conflict, contestation and antagonistic attachments involved.

\section{Discussion}

Our analysis of this transition arena endorses Hajer's and Nahuis' claim that the design of a setting strongly affects public involvement in issues such as climate change. As argued, the urban government of Ghent established the arena as a means to 'co-create' the transition towards a climate neutral city. Through this dramaturgical case study, we took a closer look at this process of co-creation by examining what the arena's setting does in shaping and transforming not only the issue at stake but also the public involved in it (Hajer, 2005). We observed that the design of this setting indeed affects "what is said, what can be said, and what can be said with influence' and how it predominantly does so by creating room for issue definitions that assemble shared attachments while downplaying the constraints antagonistic attachments put on each other. As such, the case study allowed us to explore the micro-politics of this transition arena as a situated practice and to grasp how the power relations that permeate and produce this space (Cornwall, 2002) affect the public-isation or privatisation of climate change. In our conclusions, we will argue how this gives rise to a particular approach to the development of a climate literate public.

Our analysis of the transition arena's scripting shows that 'what is said and what can be said (with influence)' depends on 'who' is allowed to speak and 'how' the characters in the play are expected to speak. Put differently, it depends on the setting's access conditions and cues for appropriate behaviour. Rather than a 'site of radical possibility' made and shaped by the participants themselves - and for themselves - this transition arena can be regarded as a 'domesticated site of invited participation' (Cornwall, 2002). By restricting the possibility of 'thinking outside the box', that is to say outside of the urban government's conception of a climate neutral city, people and issues are relocated within the prevailing order. The selection and assessment of arena members according to specific expectations (i.e. the willingness and ability to contribute to the urban 
government's ambition of climate neutrality in accordance with the proposed methods and strategies) as well as the role attributed to the engineers of the climate team gave shape to a sharp division between, on the one hand, key actors who can co-create an image of a climate neutral city and, on the other, an audience to which this story has to be 'sold' through a 'transition in the minds'. This contributes to privatisation through a consensual account of climate neutrality that tends to reduce public involvement to a topdown, expertocratic transfer of information in the pursuit of behavioural adjustment. Thus, this 'deficit model' approach of public engagement (Wynne, 2006) creates a domesticated space for participation in which some participants' political agency is almost entirely neutralised (Cornwall, 2002). As argued, the arena wants to be a platform where a variety of actors can 'learn from each other', 'by doing'. Yet, its scripting gives rise to in- and exclusionary mechanisms as to who is expected to learn from whom. This observation aligns with critical analyses of how social learning practices risk to be reduced to consensus-driven participation procedures and, thus, to an instrument for persuasion and normalisation (Van Duffel et al., 2001; Wildemeersch and Vandenabeele 2007).

Our analysis of the transition arena's staging shows how this serves as what Foucault calls a 'political technology' that bounds what is sayable and doable. Our case study shows that, as Cornwall (2002) argues, who determines the form participation takes - e.g. the choice of methods or techniques, who facilitates and how - is critical for assessing participatory practices and understanding their power dynamics. We found how the particular organisation of interactions within this arena (the employed activities, methodologies, artefacts, etc.) did not foster (time for) an in-depth exploration of the issue of climate neutrality. As indicated, the arena is primarily set up to stimulate people 'to do something' against climate change, to 'sell a story' and to realise a 'transition in the minds'. One of the interviewees explicitly defined these ambitions as a form of 'education for sustainable development'. Yet, as documented above, it is increasingly argued that education in the light of sustainability issues requires creating time and space to thoroughly study the issues at stake and to articulate, explore, and confront the diverse concerns and commitments involved (Ashley, 2005; Van Poeck and Vandenabeele, 2014; Van Poeck et al., 2015). As Devolder and Block (2015, p.3270) argue, creating a climate neutral city requires 'substantive talks and detailed discussions' about the type of cities we want to live in and about a shared understanding of the issues at stake and how these affect urban systems. This arena, however, focussed on doing rather than on studying. Marres (2005) emphasises that a focus on 'acting' and on 'managing' issues makes public-isation impossible as the success of such a mode of problem solving depends precisely on the avoidance of an overt controversy over divergent attachments that are intertwined in an affair.

Our analysis of the transition arena's performance reveals how the micro-politics of contextualised interactions and the power dynamics within them affect "what is said, what can be said and what can be said with influence" and as such "define the very boundaries of action" [Cornwall, (2002), p.8]. Our analysis of the interactions that took place in the subgroup discussion about 'waste is history' illustrate Foucault's (1975) claim that 'discourses shape not only what is said and done, but also what is sayable and doable' and constitute 'what counts as knowledge and whose knowledge counts' [Cornwall, (2002), p.8]. We observed forms of discursive closure that bound what can be discussed (e.g. consuming differently rather than consuming less) and framed how the issue of climate neutrality emerged (e.g. as a technical matter rather than something that 
requires fundamental socio-economic change). These framings not only affect how issues are debated but also how the participants and their perspectives are viewed and whose contributions are regarded legitimate (e.g. the professor's knowledge counts more than the university employee's). The empirical material quoted above shows examples of what Mathiesen (1980) calls 'defining-in' and 'defining-out' (Sim, 2009; Rice, 2010). Defining-in is about framing the issues at stake by transforming contradiction into accord, by co-opting divergent perspectives into hegemonic, status-quo reinforcing ones. This is what happened, for instance, when the university employee's concern for the inherent unsustainability of the economic organisation of society became re-framed as a technical matter of 'repair parts'. Defining-out, then, is about transforming alternatives that challenge the fundamentals of prevailing systems into irrelevance. We observed this, for example, when the suggestion to promote the use of refillable milk bottles was downplayed as 'not really feasible' or when the target to completely eliminate incineration was deleted because it would render the arena 'unreliable'. In so doing, public-ising interventions were often counteracted by privatising moves resulting in the (re-)containment of controversy over issue definitions. Thus, the mutual exclusivity of divergent points of view, values, concerns, knowledge claims, arguments, etc. was sidestepped and suggestions for actions that are irreconcilable with hegemonic solutions were downplayed. Hence, we can question the arena's potential as a space for 'transformative learning' (Jackson, 2011). After all, our analysis reveals that this setting considerably limits the occasions to break away from prevailing world views, assumptions and notions of sustainability and development and to explore and create new ones.

\section{Conclusions}

We showed how the setting of the transition arena simultaneously shaped a very particular public around a very particularly framed issue of climate neutrality. Yet, as Gomart and Hajer (2003) remind us, we should not slip into the illusion that a neutral, unbiased setting can be realised. The design of a setting never neutrally represents the public and the issue: it always constructs and transforms them and, thus, inevitably implies aspects of power and inclusion and exclusion. A 'good' setting, then, is "not one which is neutral, but one which deforms, constrains and enables in interesting ways" [Gomart and Hajer, (2003), p.39]. In line with our interest in the educational dimension of participatory practices, we address the question how to conceive of an 'interesting' setting in view of its educational potential. Therefore, we connect our analysis to the abovementioned search for a 'public pedagogy'.

Biesta (2012) argues for keeping open the opportunities to create a public sphere where people can take initiative, begin something new, do something that has not been done before. This concern for 'publicness', he emphasises, is currently threatened by the reduction of plurality and controversy through the homogenisation and purification of public spaces. Indeed, we observed and described how this transition arena, too, tends to "prescribe and police what can be done and said' as well as 'what is proper and what is deviant" [Biesta, (2012), p.689]. Through, for instance, interventions of 'defining-in' and 'defining-out' divergent perspectives, the setting of this arena reduces the space to enact contestation and controversy over irreconcilable commitments to the issue at stake. Thus, the concern for publicness is constrained. Rather than creating a public sphere in which 
people encounter plural views and develop a multi-dimensional understanding of the issues at stake by exploring the intimate entanglement of public and private interests, the diversity of private views, positions and interests is sublimated into a singular conception of the public good, i.e. a very particularly framed idea of a climate neutral city (Cornwall 2002). Yet, as Foucault emphasises, such bounded spaces of managed, controlled and invited participation are in themselves always already sites of resistance ${ }^{5}$, productive as they are of possibilities for subversion (Cornwall, 2002). Keeping open this space of possibility, we will argue, is vital in view of a public pedagogy in the face of sustainability issues.

As such, the search for an alternative conception of climate literacy and teaching and learning about global climate change as a political-educational process in our view implies a reconsideration of the abovementioned tension that goes with a two-tiered path of 'studying' and 'doing'. A one-sided emphasis on doing - as our case study shows reduces learning to a matter of instruction - a transition in the minds. Education, then, loses its intrinsic value and becomes just another manifestation of politics, but by other means (Masschelein and Simons, 2012) and the concern for publicness is downplayed by the utmost political pursuit of closure, that is, of finding a settlement for an issue (Marres, 2005). Yet, the development of a climate literate public cannot be limited to learning predefined answers but should rather enable people to think critically in relation to taken-for-granted norms and by opening-up democratic spaces where people can discuss and discover options through the exploration, evaluation, and critique of emerging ideas and the creative contribution to their development (Wals and Jickling, 2002; Osberg and Biesta, 2010; Hasslöf and Malmberg, 2014). This implies moving beyond mere functional (the acquisition of particular skills and knowledge) and cultural environmental literacy (linking the learner with a dominant value system) but requires the development of critical environmental literacy (Stables, 1998). The latter is about developing an understanding of the factors that contribute to environmental change and exploring and developing a personal response to it. In the light of climate change, this involves the ability to explore - or to 'study' - questions such as: 'What does global warming and a climate neutral city mean to me?'; 'What does it mean to us/others?'; What are the consequences of carrying on in this way?'; 'Should we act differently, and if so how?'; 'How do we translate our values in effective action?'; etc.

Hence, a vital educational challenge within such participatory approaches is to keep open a public space where controversy can be enacted and explored and where new, creative possibilities for the future might open-up. All this points to a less prescriptive form of education in line with Dewey's $(1925,1934,1938)$ transactional view in which the self and the world undergo simultaneous re-creation: experience transforms through peoples' encounters with the world. Every new encounter with the world reconstitutes both the people and the world (Caiman and Lundegård, 2014). What is actually at stake in education, then, is the kind of person one is to become as well as the kind of world that is in the making (Garrison et al., 2015). Viewed this way, education takes a strong political stand: "not just changing the world but giving others the chance to do so" [Venturini, (2010), p.269]. As the public-isation of issues plays an important role in preparing the ground for public involvement (Marres, 2005), a concern for publicness appears to be crucial for education in the context of sustainability issues. 


\section{References}

Ashley, M. (2005) 'Tensions between indoctrination and the development of judgement: the case against early closure', Environmental Education Research, Vol. 11 No. 2, pp.187-197.

Bereiter, C. (2002) Education and Mind in the Knowledge Age, Lawrence Erlbaum, Hillsdale.

Biesta, G. (2004) 'Democracy - a problem for education or an educational problem?', in Englund, T. (Ed.): Five Professors on Education and Democracy, pp.89-109, University Örebro, Örebro.

Biesta, G. (2012) 'Becoming public: public pedagogy, citizenship and the public sphere' Social \& Cultural Geography, Vol. 13, No. 7, pp.683-697.

Caiman, C. and Lundegård, I. (2014) 'Pre-school children's agency in learning for sustainable development', Environmental Education Research, Vol. 20, No. 4, pp.437-459.

Clover, D.E. and Hill, L.H. (2003) 'Learning patterns of landscape and life', New Directions for Adult and Continuing Education, No. 99, pp.89-95.

Cornwall, A. (2002) Making Spaces, Changing Places: Situating Participation in Development, IDS Working Paper 170, Institute of Development Studies, Brighton.

Cornwall, A. and Coelho, V.S.P. (2007) Spaces for Change? The Politics of Citizen Participation in New Democratic Arenas, Zed Books, London.

Devolder, S. and Block, T. (2015) 'Transition thinking incorporated: towards a new discussion. Framework on sustainable urban projects', Sustainability, Vol. 7, No. 3, pp.3269-3289.

Dewey, J. (1925/1958) Experience and Nature, Dover, New York.

Dewey, J. (1934/1980) Art as Experience, Perigee Books, New York.

Dewey, J. (1938/1997) Experience and Education, Touchstone, New York.

Engeström, Y. (1999) 'Innovative learning in work teams: analyzing cycles of knowledge creation in practice', in Engeström, Y., Miettinen, R. and Punamäki R-L. (Eds.): Perspectives on Activity Theory, pp.377-404, Cambridge University Press, Cambridge.

Ferreira, J. (2009) 'Unsettling orthodoxies: education for the environment/for sustainability', Environmental Education Research, Vol. 15, No. 5, pp.607-260.

Finger, M. and Asún, J.M. (2001) Adult Education at the Crossroads. Learning Our Way Out, Zed Books, London and New York.

Foucault, M. (1975) Discipline and Punish, Penguin, Harmondsworth.

Garrison, J., Östman, L. and Håkansson, M. (2015) 'The creative use of companion values in environmental education and education for sustainable development: exploring the educative moment', Environmental Education Research, Vol. 21, No. 2, pp.183-204.

Goeminne, G. (2011) 'Has science ever been normal? On the need and impossibility of a sustainability science', Futures, Vol. 43, No. 6, pp.627-636.

Gomart, E. and Hajer, M. (2003) 'Is that politics? For an inquiry into forms in contemporary politics', in Joerges, B. and Nowotny, H. (Eds.): Social Studies of Science and Technology: Looking Back Ahead, pp.33-61, Kluwer Academic Publishers, Dordrecht.

Hajer, M. (2005) 'Setting the stage. A dramaturgy of policy deliberation', Administration \& Society, Vol. 36, No. 6, pp.624-647.

Hasslöf, H. and Malmberg, C. (2014) 'Critical thinking as room for subjectification in education for sustainable development', Environmental Education Research [pre-published online] http://dx.doi.org/10.1080/13504622.2014.940854 (accessed 31 October 2014).

Hoppe, R. (2011) The Governance of Problems: Puzzling, Powering and Participation, Policy Press, Bristol.

Jackson, M.G. (2011) 'The real challenge of ESD', Journal of Education for Sustainable Development, Vol. 5, No. 1, pp.27-37.

Jasanoff, S. (2004) States of Knowledge. The Co-Production of Science and Social Order, Routledge, London/New York. 
Kemp, R., Loorbach, D. and Rotmans, J. (2007) 'Transition management as a model for managing processes of co-evolution towards sustainable development', International Journal of Sustainable Development \& World Ecology, Vol. 14, No. 1, pp.78-91.

Marres, N. (2005) No Issue, No Public. Democratic Deficits After the Displacement of Politics, Unpublished PhD Thesis, University of Amsterdam, Amsterdam, The Netherlands.

Masschelein, J. and Simons, M. (2012) In Defence of the School. A Public Issue, E-ducation, Culture \& Society Publishers, Leuven.

Mathiesen (1980) Law, Society and Political Action, Academic Press, London.

Nahuis, R. (2009) The Politics of Displacement. Towards a Framework for Democratic Evaluation, Innovation Studies Utrecht Working Paper Series, ISU Working Paper \#08.09, Universiteit Utrecht, Utrecht.

Nonaka, I. and Takeuchi, H. (1995) The Knowledge-Creating Company: How Japanese Companies Create the Dynamics of Innovation, Oxford University Press, New York.

Osberg, D. and Biesta, G. (2010) 'The end/s of education: complexity and the conundrum of the inclusive educational curriculum', International Journal of Inclusive Education, Vol. 14, No. 6, pp.593-607.

Paavola, S., Lipponen, L. and Hakkarainen, K. (2004) 'Models of innovative knowledge communities and three metaphors of learning', Review of Educational Research, Vol. 74, No. 4, pp.557-576.

Patton, M.Q. (2002) Qualitative Research \& Evaluation Methods. Sage Publications, Thousand Oaks, London/New Delhi.

Postma, D.W. (2004) Because We Are Human. A Philosophical Inquiry into Discourses of Environmental Education from the Perspective of Sustainable Development and Man's Caring Responsibility, Unpublished $\mathrm{PhD}$ Thesis, University of Leuven/Radboud Universiteit Nijmegen, Leuven/Nijmegen, Belgium/The Netherlands.

Rice, S. (2010) 'The challenge of remaining 'unfinished' in the campaign for justice', Paper to the 2010 National CLC Conference, 26 October 2010.

Scrase, I. and Smith, A. (2009) 'The (non-)politics of managing low carbon socio-technical transitions', Environmental Politics, Vol. 18, No. 5, pp.707-726.

Sim, J. (2009) Punishment and Prisons. Power and the Carceral State, SAGE Publications Ltd, Los Angeles, London, New Delhi, Singapore, Washington DC.

Simons, M. and Masschelein, J. (2006) 'The learning society and governmentality: an introduction', Educational Philosophy and Theory, Vol. 38, No. 4, pp.417-430.

Simons, M. and Masschelein, J. (2009) 'The public and its university: beyond learning for civic employability', European Educational Research Journal, Vol. 8, No. 2, pp.204-217.

Simons, M. and Masschelein, J. (2010) 'Governmental, political and pedagogic subjectivation: foucault with Rancière', Educational Philosophy and Theory, Vol. 42, Nos. 5/6, pp.588-605.

Stables, A. (1998) 'Environmental literacy: functional, cultural, critical. The case of the SCAA guidelines', Environmental Education Research, Vol. 4, No. 2, pp.155-164.

Stad Gent (2011) Naar een duurzame stad: meer dan een city-trip! Over 'transities' en 'transitiemanagement'. Versie 30 mei 2011, Unpublished document.

Sumner, J. (2003) 'Learning our way in: sustainable learning and the civil commons', Convergence, Vol. XXXVI, No. 1, pp.21-30.

Sund, L. and Öhman, J. (2014) 'On the need to repoliticise environmental and sustainability education: rethinking the postpolitical consensus', Environmental Education Research, Vol. 20, No. 5, pp.639-659.

Van Duffel, K., Janssens, C. and Wildemeersch, D. (2001) 'Policy planning as social learning', in Schemmann, M. and Bron, M. (Eds.): Adult Education and Democratic Citizenship IV, Impuls Publisher, Krakow. 
Van Poeck, K. and Vandenabeele, J. (2014) Education as a response to sustainability issues, European Journal for Research on the Education and Learning of Adults, Vol. 5, No. 2, pp.221-236.

Van Poeck, K., Goeminne, G. and Vandenabeele, J. (2015) 'Revisiting the democratic paradox of environmental and sustainability education: sustainability issues as matters of concern', Environmental Education Research, pre-published online [online] http://dx.doi.org/10.1080/13504622.2014.966659 (accessed 22 October 2014).

Van Poeck, K., Vandenabeele, J. and Bruyninckx, H. (2014) 'Taking stock of the UN Decade of education for sustainable development: the policy-making process in Flanders', Environmental Education Research, Vol. 20, No. 5, pp.695-717.

Vare, P. and Scott, W. (2007) 'Learning for a change: exploring the relationship between education and sustainable development', Journal of Education for Sustainable Development, Vol. 1, No. 2, pp.191-198.

Venturini, T. (2010) 'Diving in magma: how to explore controversies with actor-network theory', Public Understanding of Science, Vol. 19, No. 3, pp.258-273.

Wals, A.E.J. and Jickling, B. (2002) "'Sustainability" in higher education: from doublethink and newspeak to critical thinking and meaningful learning', International Journal of Sustainability in Higher Education, Vol. 3, No. 3, pp.221-232.

Wildemeersch, D. and Vandenabeele, J. (2007) 'Relocating social learning as a democratic practice', in van der Veen, R., Wildemeersch, D., Youngblood, J. and Marsick, V. (Eds.): Democratic Practices as Learning Opportunities, pp.23-36, Sense Publishers, Rotterdam.

Wynne, B. (2006) 'Public engagement as a means of restoring public trust in science - hitting the notes, but missing the music?', Public Health Genomics, Vol. 9, No. 3, pp.211-220.

\section{Notes}

1 Besides such 'unstructured', 'wicked' sustainability problems that are characterised by a lack of agreement on norms and values at stake and a lack of certainty regarding the required and available knowledge, some (aspects of) sustainability problems can be considered as 'structured' and 'moderately structured' (i.e. either the ethical acceptability of goals or the suitable means are subject to discussion) (Hoppe, 2011). Realising that in such cases the role of learning is less contested, the focus of this article is on the role of education in the face of uncertain and controversial sustainability issues such as climate change.

2 Dutch Research Institute for Transitions.

3 The organisers asked us not to do so as their initiative - perceived as an innovative practice - received attention from many researchers, students, etc. and they wanted to prevent arena members from being overloaded with such requests.

4 The 22 most polluting companies in the city of Ghent (e.g. ArcelorMittal, steel and mining company), however, are excluded from the city's climate strategy and its calculations due to the EU emissions trading system.

5 Indeed, during our observation of the Climate Forum, for example, we witnessed how a sub-group of the expanded transition arena (cf. above) discussed the topic of 'urban farming' and in so doing managed to resist the above described power dynamics and its effects. They actually created a sub-setting within this arena where the consensual, hegemonic framing of climate neutrality was interrupted and alternative views became 'sayable' and 'doable'. It would, however, move beyond the scope of the present article to elaborate this extensively. 